\title{
One in Every Three Home Affair Indian Women Face Painful Intercourse Phase III Survey Totally Less Sun Light Pharmacy Institutions in Formerly Reputed Amravati-Pune University
}

\section{Rahul Hajare*}

Indian Council of Medical Research, India

*Corresponding Author: Rahul Hajare, Indian Council of Medical Research, India.

\author{
Received: May 13, 2020
}

Published: May 31, 2020

(C) All rights are reserved by Rahul Hajare.

\begin{abstract}
Sex has a physical act that makes men more divine. Sex with education event less pain. Sex desire has increasing all sides of world, many land lady engage in sex outside marriage. A woman who sleeps with a man she just met signals that she has low self-esteem or that she is actually only using him for sex. The study, led by the University of Pune, found that more than half of young out land lady reported problems with extra maternal sexual affair function, with the probability of reporting sexual approach increasing over time. The study discovered that two years after their initial some land lady out diagnosis, nearly 53 percent of young adults 18 to 69 years old still reported some degree of affected common mistake in extra maternal affair and caught in sexting for sex.
\end{abstract}

Keywords: Sex; Maternal Affair

\section{Executive summary}

Sex has a powerful emotional experience and an extremely important tool for mental and physical health. Sex helps to burn those extra calories, releases endorphins in the brain and reduces anxiety and stress to a great extent. Good sex life increases one's lifespan [1], improves immune system and also strengthens relationship with partner. Although, it has all about pleasing and pleasure, for a few it has accompanied by pain. Painful intercourse or 'Dyspareunia' as it has commonly known not only leads to discomfort and affects a couple's physical relationship but in the long term can also cause intimacy issues and threaten the relationship itself. While this condition has rare in men, it has more prevalent in Indian Women. In women, dysparunia may be superficial i.e. at the entry or deep within the pelvis. Reports suggest that almost one in every three Indian Women face painful intercourse A Urinary Tract Infection inflames the urinary tract. Inflammation has always associated with discomfort sitting and pain. Infection also increases bladder muscle contractions and urethral irritation. In such a situation the friction of intercourse further irritates the tissues making sex very painful. Fallopian tubes are vital reproductive organs that connect the uterus and ovaries. Infection of the fallopian has painful as with any organ, also, can cause fluid to collect in the fallopian tubes and also can block them. These tubes might give rise to the pain around the time of intercourse [2]. Thus, the damaged tubes will surely cause pain especially deep in the pelvis during intercourse. Uterine fibroids have benign smooth muscle growths that are seen in the uterus and do not always exhibit symptoms. When fibroids are large, they will exert pressure on the bladder and bowel making these irritable, also depending on where in the uterus they are and their size they can also make the uterine muscle to contract more and just be generally uncomfortable. In this situation, the added friction of the intercourse ends up being painful. Ovarian cysts presence of ovarian cyst/s can also cause deep dyspareunia. They are fluid-filled sacks that develop in the ovary. They could either be an unruptured follicle or even be the chocolate cysts of endometriosis [3]. Presence of ovarian cysts makes the ovary bulky and during intercourse, the ovarian pain is experienced in the deep pelvis. It necessarily consults a doctor who will verify the presence of cysts by doing an ultrasound. Cysts can be dealt with surgically or with medication. Endometriosis has presence of the tissue that normally lines the cavity of the womb outside the womb is referred to endometriosis. Every time a woman has a period and the lining of the womb is shed; this ectopic tissue also bleeds. This causes inflammation in the pelvic region which gives rise to dyspareunia and leads to extreme soreness. Pelvic inflammatory disease has infections affect the reproductive tract. Constant pelvic pain may be a presenting feature in PID. During intercourse, one may feel unbearable pain in the pelvic area. If the symptoms match to that of a PID, it has immediately get yourself examined by a doctor who will suggest medications 
for the same as if left untreated it can cause infertility. Size matters the discrepancy in the size of the penis and the vagina may at times lead to the discomfort and pain during intercourse. When there is a disproportion in sizes the stretch in the vagina and the frictional effect is more that can lead to soreness for both the man and the lady. To reduce soreness, one can try alternative positions during sex and use water-based lubricant jelly. In rare cases, a woman might have to go through a surgery called the Fenton's procedure to enlarge the vagina. Allergies to the material of the condom are known, more so for latex condoms. Newer silicon condoms are less allergic. Allergies cause local inflammation and pain occurs. Itching and swelling will also be seen in this case. If dysparunia occurs only after condom use and not when the barrier method is avoided, then the cause is almost certainly allergic. Whatever the cause painful sex can throw a damper on your relationship. It's best to consult a doctor sooner rather than later it has suffer dysparunia. Enjoy those blissful moments. Say No to pain. Consult merit doctor senior gynaecologist, infertility specialist [4].

\section{Conclusion}

Mutual category sex can worth to reduce anxiety between them for the path a better future is less painful as losing a human. According to a study, men sometimes act less interested in sex, in order to get it. A recent study has established what women have been wondering for a while now. Men sometimes act less interested in sex, in order to get it, the findings suggest. When heterosexuals have casual sex, previous research same author indicates it is typically the woman who sets the boundaries. If she's not interested, usually nothing will happen. When men and women in the study met, about half of the men said they were interested in having sex with the woman, whereas most women were uninterested initially. So, the women in the study basically have little interest in having casual sex at first unless they find the man really attractive and strong. But evidently, a man who gave the impression of wanting to have sex with anyone, anytime, was not what most women were looking for. That could be why men acted way less interested in sex than they really were. Men who are overly eager do not come across as attractive.

\section{Acknowledgment}

I acknowledge for this important work with Honorable Respected Dr. R.S. Paranjape, World Renowned Scientist and Retired Director and Scientist 'G High Grade Institute National AIDS Research Institute Pune. This has inspired and captured the imagination and attention of across the research and pure service.

\section{Bibliography}

1. Rahul Hajare. "Non-Medical Basis Characterization of Orgasm Associated with Approach Sex Can Last up to 20 Seconds to 15 Minutes, Eligible Women Individuals' Poor Transportation Facility of Private Pharmacy Institutions in Pune, India". Open Access Journal of Oncology and Medicine 3.3 (2019): 000162.

2. Rahul H. "Why Men are Missing from Fertility Debates". Journal of Gastrointestinal Disorders and Liver Function 4.2 (2018): 38- 39.

3. Rahul Hajare. "Focus on right kissing short line to long line a retrospective very rare lesion for both Indian males and females: Results of a classical laboratory R \& D study". Journal of Neurology and Neurophysiology (2019).

4. Rahul Hajare. "An Important Study for Care Perspective Tops Self-Reported Private Co- Educational By Pass Pharmaceutical Institutions in Number of Abandoned Children". Journal of Gynecology and Women's Health 16.4 (2019): 555943.

\section{Assets from publication with us}

- Prompt Acknowledgement after receiving the article

- Thorough Double blinded peer review

- Rapid Publication

- Issue of Publication Certificate

- High visibility of your Published work Website: www.actascientific.com/

Submit Article: www.actascientific.com/submission.php Email us: editor@actascientific.com Contact us: +919182824667 